\title{
Impact of insurance status on the survival of gallbladder cancer patients
}

\author{
Zhiqiang Chen ${ }^{1, *}$, Wen Gao ${ }^{2, *}$, Liyong $\mathrm{Pu}^{1, *}$, Long Zhang ${ }^{1}$, Guoyong Han ${ }^{1}$, Qin Zhu ${ }^{1}$, \\ Xiangcheng $\mathrm{Li}^{1}$, Jindao $\mathrm{Wu}^{1}$ and Xuehao Wang ${ }^{1}$ \\ ${ }^{1}$ Department of Liver Surgery, The First Affiliated Hospital of Nanjing Medical University, Key Laboratory on Living Donor \\ Liver Transplantation, National Health and Family Planning Commission, Nanjing, Jiangsu Province, China \\ ${ }^{2}$ Department of Oncology, The First Affiliated Hospital of Nanjing Medical University, Nanjing, Jiangsu Province, China \\ *These authors have contributed equally to the work \\ Correspondence to: Xuehao Wang, email: wangxh@njmu.edu.cn \\ Jindao Wu, email: wujindao@njmu.edu.cn \\ Xiangcheng Li, email: drxcli@njmu.edu.cn
}

Keywords: gallbladder cancer, insurance status, SEER, survival analysis

Received: March 29, $2017 \quad$ Accepted: May 06, $2017 \quad$ Published: June 06, 2017

Copyright: Chen et al. This is an open-access article distributed under the terms of the Creative Commons Attribution License 3.0 (CC BY 3.0), which permits unrestricted use, distribution, and reproduction in any medium, provided the original author and source are credited.

\section{ABSTRACT}

The prognostic significance of insurance status has been investigated in many types of malignancies, however, its impact on gallbladder cancer is yet not known. The purpose of this study was to determine the relationship between insurance status and gallbladder cancer survival. We searched the Surveillance, Epidemiology, and End Results dataset, and identified 1,729 gallbladder cancer cases. Kaplan-Meier methods and multivariable Cox regression models were used to analyze survival outcomes and risk factors. We found that individuals who had non-Medicaid insurance were more likely to be male, older, from wealthier area, and better-educated. Insurance status was confirmed as an independent prognostic factor for gallbladder cancer patients. Stratified analysis revealed that the uninsured status independently predicted unfavorable survival outcome at localized tumor stage and in white individuals. To conclude, insurance status is an important predictive factor for gallbladder cancer, and uninsured individuals are at the highest risk of death.

\section{INTRODUCTION}

Gallbladder cancer (GBC) is the fifth most common gastrointestinal malignancy and the most frequent malignancy of the biliary tract, accounting for $80 \%-95 \%$ of biliary tree cancers around the world [1]. The etiology of this tumor is complex, and there is a strong association with cholelithiasis [2]. GBC is highly fatal and usually diagnosed at advanced stages due to absence of specific clinical findings in early stages [3]. It has been reported that the age-adjusted incidence rate of GBC is 1.4 per 100,000 in the United States, and is steadily increasing with age [4-6]. Despite recent advances in its diagnostic techniques and therapeutic managements, the prognostic outcome of patients with GBC remains dismal [7].
The correlation of insurance status with survival was demonstrated in different types of cancers. A higher risk of death associated with lack of health insurance or being a Medicaid beneficiary was found in younger patients with multiple myeloma [8]. Among patients with glioblastoma multiforme, uninsured status and Medicaid insurance indicated shorter survival compared to non-Medicaid insurance [9]. Survival was significantly better in privately insured patients with hepatocellular carcinoma [10]. In colorectal cancer patients, lack of insurance and Medicaid were independently associated with worse overall survival [11]. In obvious contrast, insurance status did not influence outcomes for adolescents and young adults with acute lymphoblastic leukemia [12]. The impact of insurance status on the survival of adult patients diagnosed 
with GBC, however, has not yet been examined. In the current study, we obtained data from the Surveillance, Epidemiology, and End Results (SEER) program, aiming to evaluate the association between insurance status and GBC cause-specific survival (GCSS) in the enrolled patients.

\section{RESULTS}

\section{Patient population and characteristics}

A total of 20,148 cases diagnosed with GBC were retrieved in the SEER database. After applying the inclusion and exclusion criteria, 1,729 GBC patients diagnosed during the 7-year study period (between 2007 and 2013) in the SEER were included in the final cohort. Figure 1 demonstrates the flow diagram for patient selection in the current study. Among the enrolled patients, 1,210 (70.0\%) were females and $519(30.0 \%)$ were males. A total of 1,217 patients $(70.4 \%)$ were white, and $306(17.7 \%)$ patients were black. The median age of included patients was 57 years. In the enrolled population, 1,160 patients $(67.1 \%)$ had non-Medicaid insurance, 175 (10.1\%) were uninsured, and $394(22.8 \%)$ had Medicaid coverage. Significant differences were observed in subgroups including gender ( $P=0.001)$, age $(P<0.001)$, pathological grading $(P=0.005)$, county-level income $(P<0.001)$, county-level education $(P<0.001)$, and surgical therapy $(P<0.001)$. Compared with the uninsured individuals, individuals who had nonMedicaid insurance were more likely to be male, older, from counties with higher income, and better-educated. In addition, patients with non-Medicaid insurance were more likely to receive surgical therapy. Table 1 illustrates variations in the distribution of patient demographics and

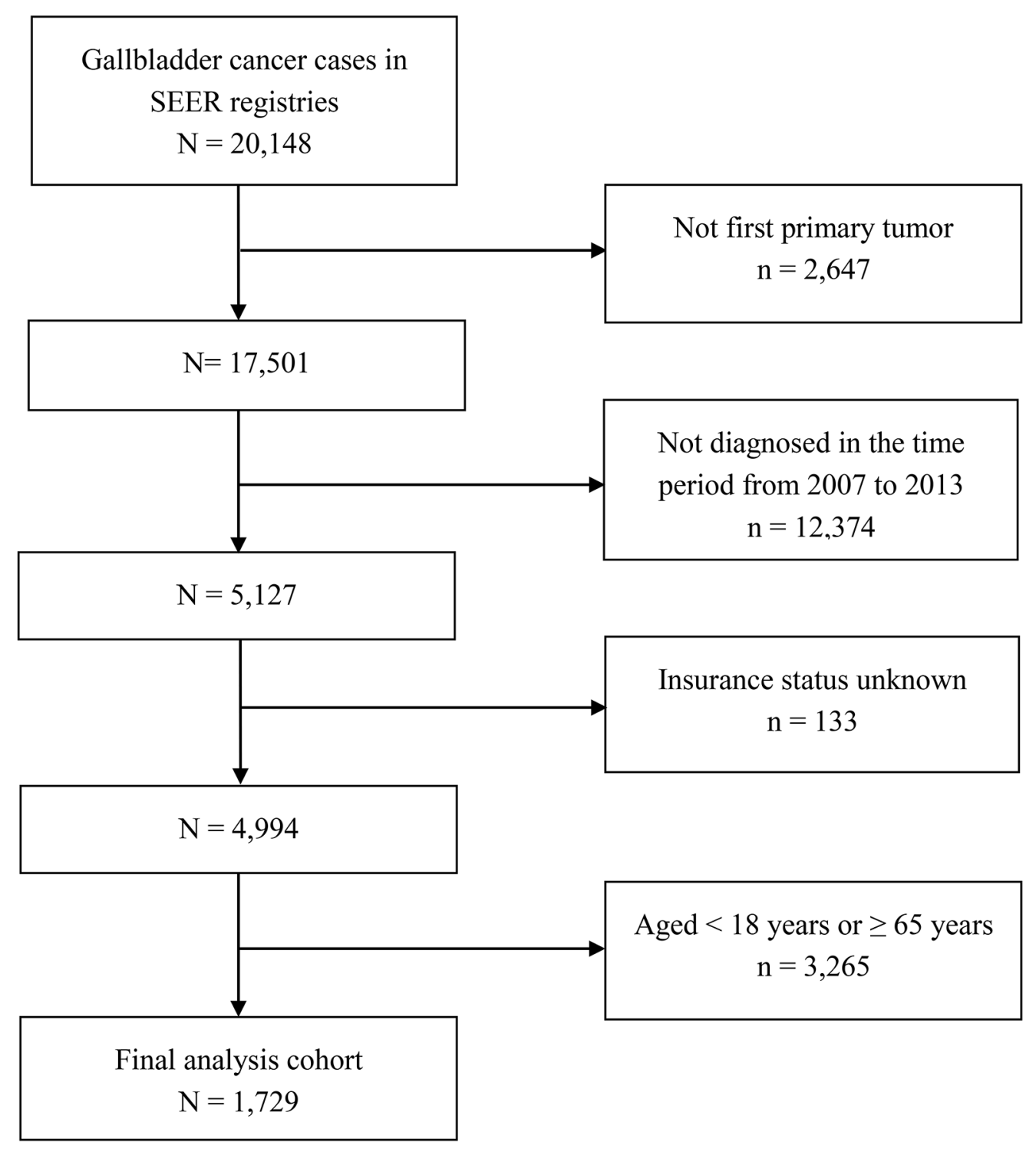

Figure 1: Flow diagram of patient selection for the current study. 
Table 1: Variations in insurance coverage in the enrolled population

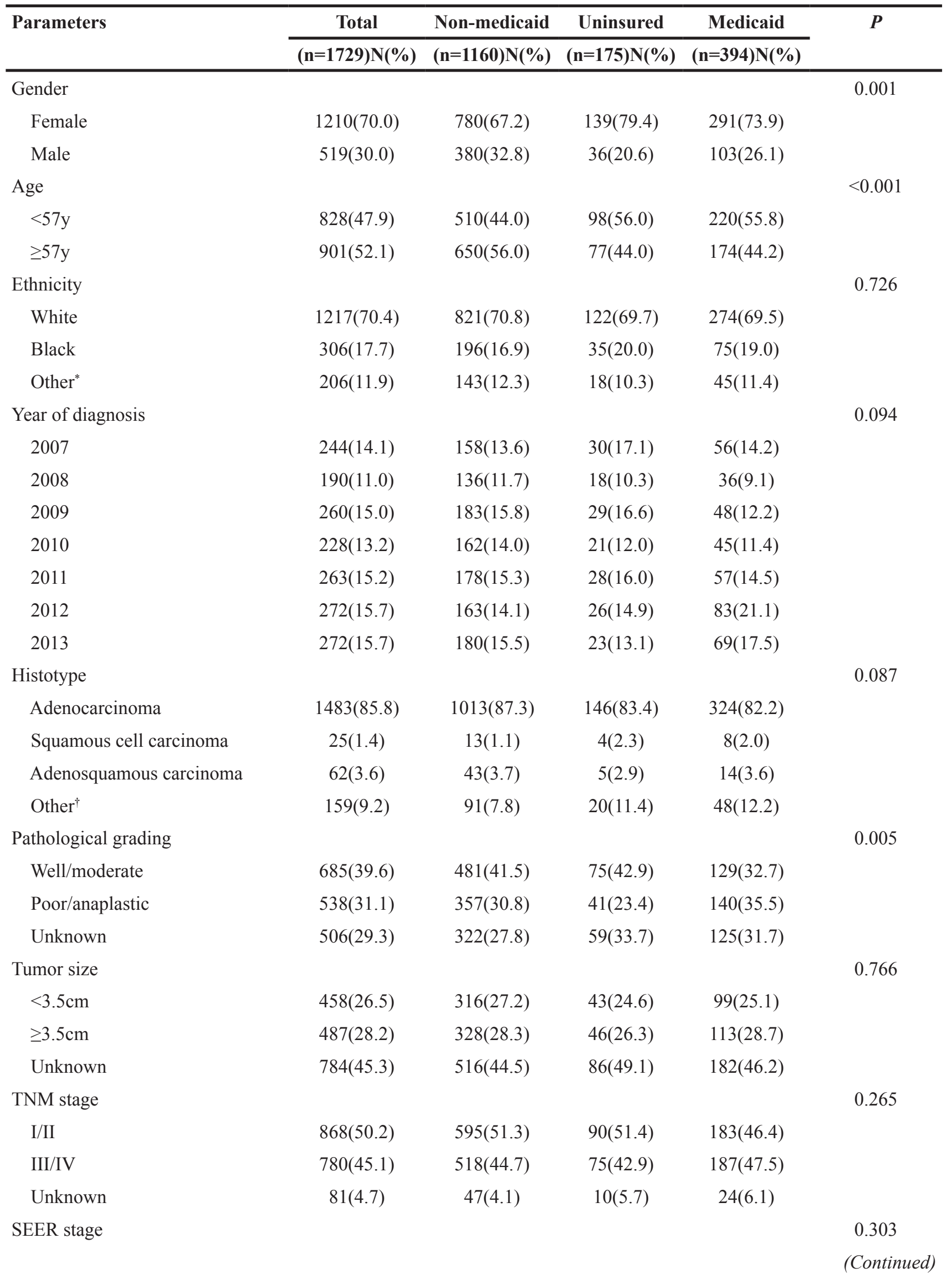




\begin{tabular}{|c|c|c|c|c|c|}
\hline \multirow[t]{2}{*}{ Parameters } & Total & Non-medicaid & Uninsured & Medicaid & $P$ \\
\hline & $(n=1729) N(\%)$ & $(n=1160) N(\%)$ & $(n=175) N(\%)$ & $(n=394) N(\%)$ & \\
\hline Localized & $469(27.1)$ & $327(28.2)$ & $53(30.3)$ & $89(22.6)$ & \\
\hline Regional & $370(21.4)$ & $241(20.8)$ & $36(20.6)$ & $93(23.6)$ & \\
\hline Distant & $862(49.9)$ & $576(49.7)$ & $82(46.9)$ & $204(51.8)$ & \\
\hline Unstaged & $28(1.6)$ & $16(1.4)$ & $4(2.3)$ & $8(2.0)$ & \\
\hline County-level income & & & & & $<0.001$ \\
\hline Quartile $1(<$ US $\$ 59,290)$ & $390(22.6)$ & $252(21.7)$ & $42(24.0)$ & $96(24.4)$ & \\
\hline Quartile 2 (US $\$ 59,290-\$ 63,670)$ & $465(26.9)$ & $269(23.2)$ & $52(29.7)$ & $144(36.5)$ & \\
\hline Quartile 3 (US $\$ 63,670-\$ 81,810$ ) & $436(25.2)$ & $309(26.6)$ & $50(28.6)$ & $77(19.5)$ & \\
\hline Quartile 4 ( $\geq$ US $\$ 81,810$ ) & $438(25.3)$ & $330(28.4)$ & $31(17.7)$ & $77(19.5)$ & \\
\hline County-level education & & & & & $<0.001$ \\
\hline Quartile $1(<21.30 \%)$ & $413(23.9)$ & $265(22.8)$ & $41(23.4)$ & $107(27.2)$ & \\
\hline Quartile $2(21.30 \%-29.68 \%)$ & $312(18.0)$ & $241(20.8)$ & $21(12.0)$ & $50(12.7)$ & \\
\hline Quartile $3(29.68 \%-36.25 \%)$ & $569(32.9)$ & $334(28.8)$ & $74(42.3)$ & $161(40.9)$ & \\
\hline Quartile $4(\geq 36.25 \%)$ & $435(25.2)$ & $320(27.6)$ & $39(22.3)$ & $76(19.3)$ & \\
\hline Surgical therapy & & & & & 0.007 \\
\hline Yes & $1152(66.6)$ & $802(69.1)$ & $109(62.3)$ & $241(61.2)$ & \\
\hline None/unknown & $577(33.4)$ & $358(30.9)$ & $66(37.7)$ & $153(38.8)$ & \\
\hline
\end{tabular}

SEER: Surveillance, Epidemiology, and End Results.

* Other includes American Indian/Alaska native, Asian/Pacific Islander, and unknown.

$\dagger$ Other cancers include signet ring, small cell, giant and spindle cell, non-small cell carcinoma, carcinoma not otherwise specified, or undifferentiated carcinoma.

tumor characteristics between different types of insurance coverage.

\section{Insurance status and GCSS}

The overall median survival of the included population was 9.0 months, with a 3-year GCSS of $12.0 \%$. The 3 -year GCSS was $27.6 \%$ in patients with non-Medicaid insurance, which was the highest compared with that in uninsured patients $(21.4 \%)$ and in patients with Medicaid coverage (23.7\%); all differences were significant according to the univariate log-rank test $(P=0.001)$ (Figure 2$)$. Gender $(P=0.003)$, ethnicity $(P=0.003)$, histotype $(P<0.001)$, pathological grading $(P<0.001)$, TNM stage $(P<0.001)$, tumor size $(P<0.001)$, SEER stage $(P<0.001)$ and surgical therapy $(P<0.001)$ were regarded as significant predictive factors for survival outcome by univariate analysis (Table 2). Multivariate analysis was carried out using the Cox proportional hazard model. The following nine factors were verified as independent prognostic factors for GBC (Table 2), including insurance status (uninsured, hazard ratio [HR] $1.279,95 \%$ confidence interval [CI] 1.042-1.569), gender (male, HR 1.173, 95\% CI 1.030-1.335), ethnicity (black, HR 1.227, 95\% CI 1.053-1.430), histotype (squamous cell carcinoma, HR 1.884, 95\% CI 1.213-2.925; adenosquamous carcinoma, HR 1.488, 95\% CI 1.098 2.017), pathological grade (poor/anaplastic, HR 1.738, $95 \%$ CI $1.487-2.030)$, tumor size ( $\geq 3.5 \mathrm{~cm}$, HR 1.284 , 95\% CI 1.074-1.536), TNM stage (III/IV, HR 1.765, 95\% CI 1.407-2.214), SEER stage (regional, HR 2.208, 95\% CI 1.773-2.750; distant, HR 2.523, 95\% CI 1.906-3.338), and surgical therapy (none/unknown, HR 1.813, 95\% CI 1.533-2.143).

\section{Subgroup analysis of insurance status on GCSS based on SEER stage}

As shown in Table 3 and Figure 3A-3C, we examined the effects of insurance status on GCSS at each SEER stage. Univariate analysis showed that patients with non-Medicaid insurance had the highest survival rate for both localized stage tumors and distant stage tumors. Individuals with non-Medicaid insurance had a $26.8 \%$ increase in 3-year GCSS compared with uninsured individuals $(68.4 \%$ vs $41.6 \%, P<0.001)$, 
and a $9.5 \%$ increase compared with individuals with Medicaid coverage $(68.4 \%$ vs $58.9 \%, P=0.020)$ for localized stage tumors. For distant stage tumors, non-Medicaid patients had a $0.6 \%$ increase in 3 -year GCSS compared to uninsured patients $(7.1 \%$ vs $6.5 \%$, $P=0.012$ ), and a $1.6 \%$ increase compared to Medicaid recipients $(7.1 \%$ vs $5.5 \%, P=0.031)$. The significant differences, however, were not observed in patients with regional stage tumors according to the results of univariate analysis $(P=0.343)$. Multivariate Cox regression analyses were performed for different SEER stages. Insurance status was validated as an independent predictor of GBC survival at localized stage (uninsured, HR 2.122, 95\% CI 1.297-3.473; Medicaid, HR 1.590, $95 \%$ CI 1.038-2.435). No significant results were found at SEER regional or distant stage in multivariate analyses.

\section{Subgroup analysis of insurance status on GCSS according to ethnicity}

We further assessed the correlation of insurance status with cancer cause-specific survival according to different ethnicities (Table 4 and Figure 3D-3F). Compared to uninsured patients and Medicaid beneficiaries, patients with non-Medicaid insurance had the highest 3-year GCSS in all subgroups. Univariate analysis of insurance status revealed that non-Medicaid patients had a better 3-year GCSS compared to uninsured patients for white individuals (28.6\% vs $21.7 \%, P=0.019)$. Multivariate analysis confirmed the independent prognostic effect of insurance status in white individuals (uninsured, HR 1.421, 95\% CI 1.109-1.822). For black individuals, univariate analysis indicated that patients with non-Medicaid insurance had a better 3-year GCSS compared Medicaid beneficiaries $(22.1 \%$ vs $9.3 \%, P=0.002)$. The influence of insurance status on GBC survival was not

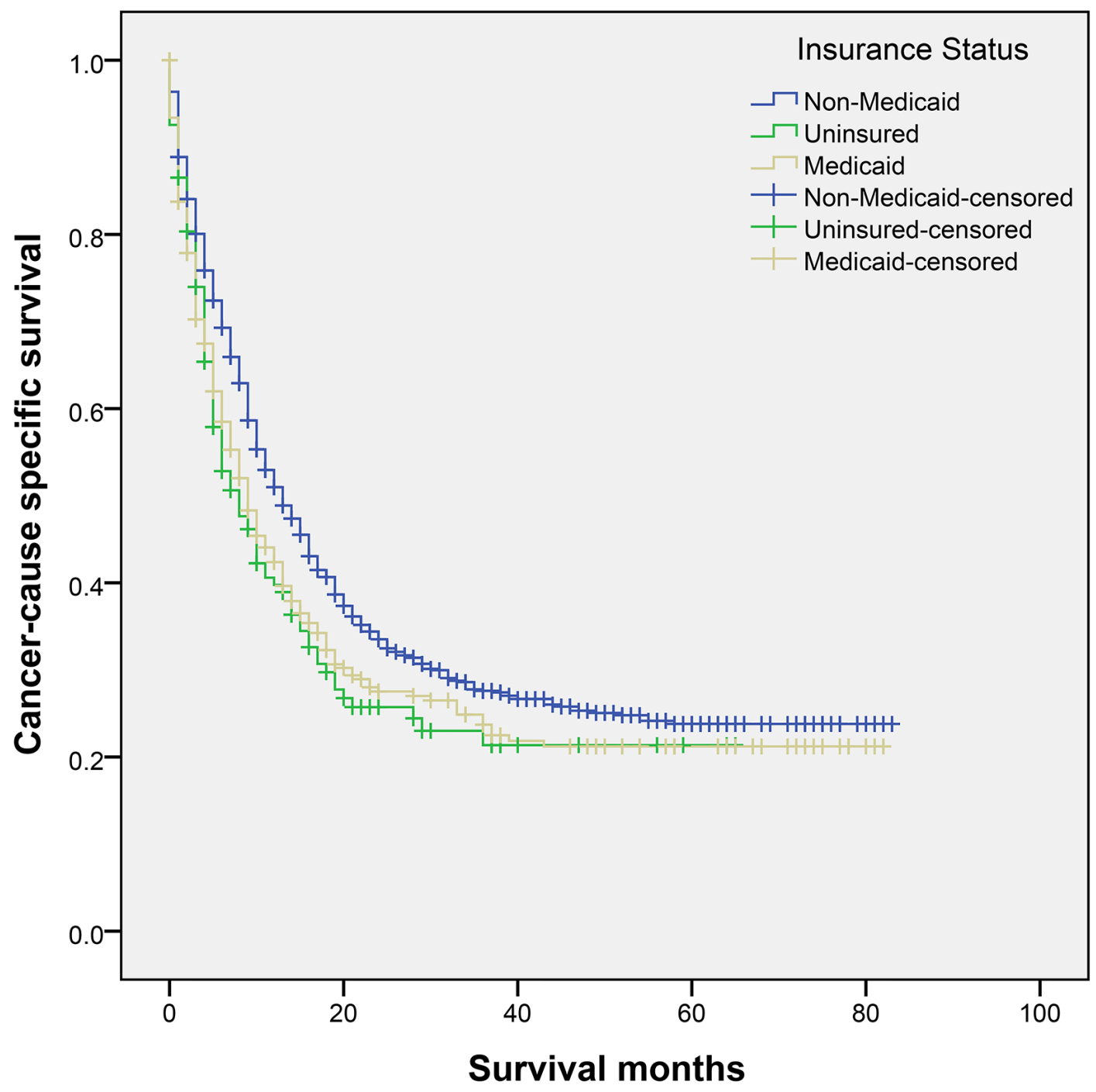

Figure 2: Survival curves in gallbladder cancer patients. $\chi 2=14.268, P=0.001$. 
Table 2: Univariate and multivariate survival analysis for evaluating the influence of insurance status on gallbladder cancer cause-specific survival in SEER database

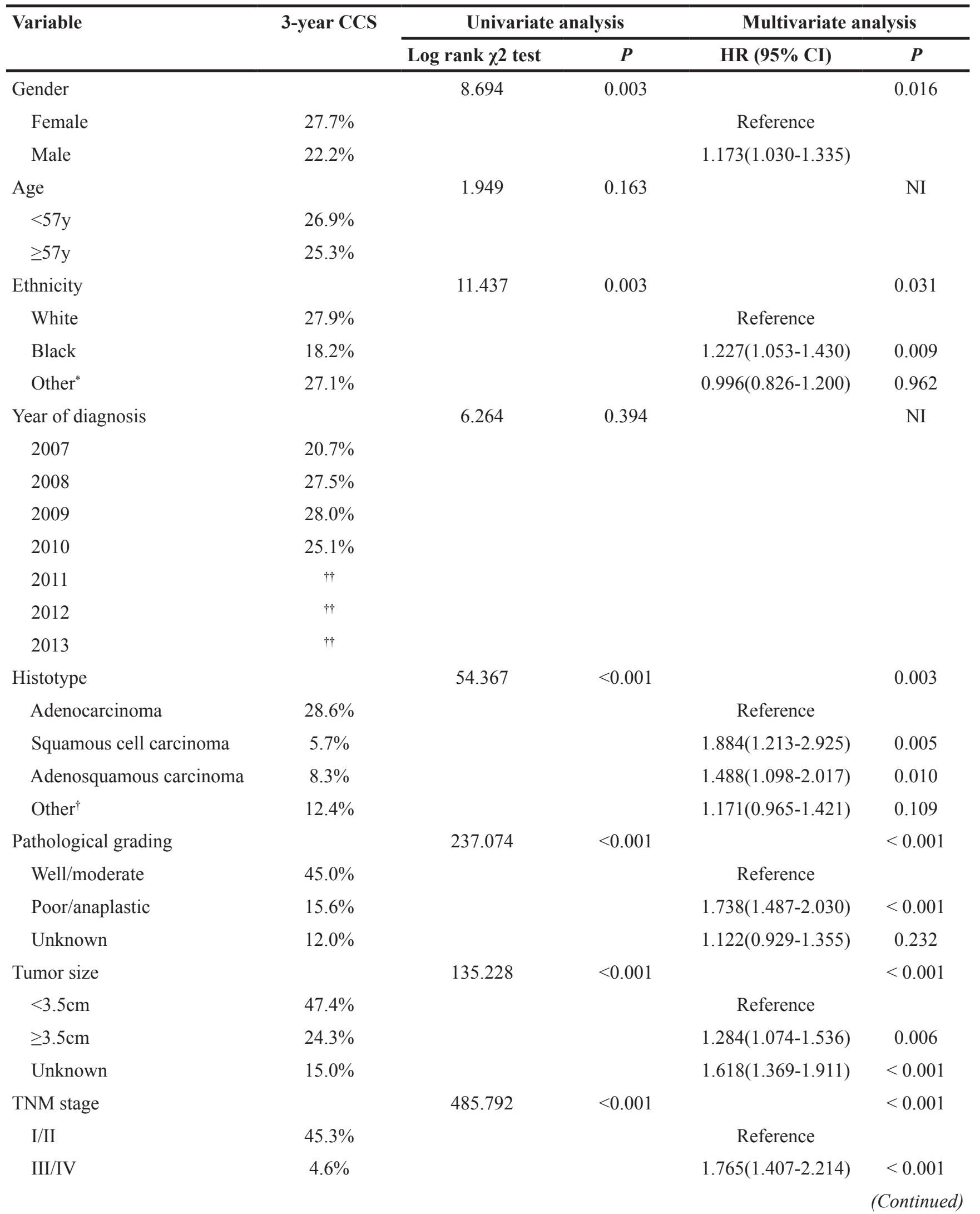




\begin{tabular}{|c|c|c|c|c|c|}
\hline \multirow[t]{2}{*}{ Variable } & \multirow[t]{2}{*}{ 3-year CCS } & \multicolumn{2}{|c|}{ Univariate analysis } & \multicolumn{2}{|c|}{ Multivariate analysis } \\
\hline & & Log rank $\chi 2$ test & $P$ & HR $(95 \%$ CI) & $P$ \\
\hline Unknown & $26.0 \%$ & & & $1.541(1.058-2.245)$ & 0.024 \\
\hline SEER stage & & 492.424 & $<0.001$ & & $<0.001$ \\
\hline Localized & $64.1 \%$ & & & Reference & \\
\hline Regional & $25.0 \%$ & & & $2.208(1.773-2.750)$ & $<0.001$ \\
\hline Distant & $6.5 \%$ & & & $2.523(1.906-3.338)$ & $<0.001$ \\
\hline Unstaged & $18.6 \%$ & & & $1.651(0.939-2.905)$ & 0.082 \\
\hline County-level income & & 0.600 & 0.896 & & NI \\
\hline Quartile $1(<$ US \$59,290) & $25.8 \%$ & & & & \\
\hline $\begin{array}{l}\text { Quartile } 2 \text { (US } \$ 59,290- \\
\$ 63,670)\end{array}$ & $28.1 \%$ & & & & \\
\hline $\begin{array}{l}\text { Quartile } 3 \text { (US } \$ 63,670 \text { - } \\
\$ 81,810 \text { ) }\end{array}$ & $26.3 \%$ & & & & \\
\hline Quartile 4 ( $\geq$ US $\$ 81,810$ ) & $23.4 \%$ & & & & \\
\hline County-level education & & 2.693 & 0.441 & & NI \\
\hline Quartile $1(<21.30 \%)$ & $30.5 \%$ & & & & \\
\hline Quartile $2(21.30 \%-29.68 \%)$ & $24.4 \%$ & & & & \\
\hline Quartile $3(29.68 \%-36.25 \%)$ & $25.5 \%$ & & & & \\
\hline Quartile $4(\geq 36.25 \%)$ & $23.6 \%$ & & & & \\
\hline Surgical therapy & & 459.917 & $<0.001$ & & $<0.001$ \\
\hline Yes & $37.4 \%$ & & & Reference & \\
\hline None/unknown & $2.9 \%$ & & & $1.813(1.533-2.143)$ & \\
\hline Insurance status & & 14.268 & 0.001 & & 0.045 \\
\hline Non-medicaid & $27.6 \%$ & & & Reference & \\
\hline Uninsured & $21.4 \%$ & & & $1.279(1.042-1.569)$ & 0.019 \\
\hline Medicaid & $23.7 \%$ & & & $1.109(0.959-1.282)$ & 0.162 \\
\hline
\end{tabular}

SEER: Surveillance, Epidemiology, and End Results; CCS: cancer cause-specific survival; HR: hazard ratio; CI: confidence interval; NI: not included in the multivariate survival analysis.

* Other includes American Indian/Alaska native, Asian/Pacific Islander, and unknown.

$\uparrow$ Other cancers include signet ring, small cell, giant and spindle cell, non-small cell carcinoma, carcinoma not otherwise specified, or undifferentiated carcinoma.

\# Because the follow-up records in SEER dataset ended in 2013, its 3-year CCS did not exist.

statistically significant in the subgroup of American Indian/ Alaska native and Asian/Pacific Islander.

\section{DISCUSSION}

GBC is a highly malignant cancer known for its aggressive biological nature and poor clinical presentation. Complete surgical resection is the only curative option available, but more than $90 \%$ of GBC patients are with un-resectable or metastatic disease [13]. Despite improved results of chemotherapy and surgery, the long-term outcome remains disappointing [14]. Thus, efforts are needed to identify factors contributing to prognosis of GBC. Previous studies have established several independent prognostic factors in patients with GBC. T stage, $\mathrm{N}$ stage, grade and histology are independent predictors of survival for gallbladder adenocarcinoma [15]. Tumor penetration of the gallbladder wall and pathologically confirmed lymph node involvement carry poor prognosis [16]. Studies in recent years have shown the importance of sociodemographic factors for survival in patients on GBC survival. It has been 
confirmed that marital status is an important prognostic risk factor for survival in patients with GBC treated with surgical resection [17]. To the best of our knowledge, our study is the first to associate insurance status with survival among patients diagnosed with GBC.

According to the results presented herein, patients with non-Medicaid insurance were more likely to be male, older, from richer area, and better-educated, which is in agreement with observations from previous studies that also utilized the SEER database [18, 19]. NonMedicaid patients had the highest 3-year cancer-specific survival compared with uninsured patients and Medicaid recipients. Both patient- and tumor-related features may contribute to the heterogeneity of the study, and exert an effect on the prognosis of GBC patients. In the current study, we controlled for several variables that might lead to heterogeneity and attempted to demonstrate the association between insurance status and GBC survival. Cox proportional hazard analysis was performed, and the uninsured status was confirmed as an independent predictive factor of shorter survival in patients with GBC after adjusting for covariates including gender, ethnicity, histotype, pathological grading, tumor size, tumor stage, and surgical therapy. Stratified analysis of survival based on different SEER stages and ethnicities revealed that the uninsured status independently predicted unfavorable survival outcome at SEER localized stage and in white individuals. However, because of insufficient data, we did not further investigate other potential contributing factors such as genetic characteristics, comorbidities, operation methods, and hospital volume. Differences in the biological, psychological and social characteristics of the enrolled individuals may lead to the heterogeneity in the study, and potentially have an influence on the results. More large-scale studies are warranted to examine the associations and explore the underlying mechanisms.

One hypothesis for the survival differences between insured and uninsured patients is that insurance status may indirectly indicate the socioeconomic status of the individual. On one hand, it has been demonstrated that residence in counties with higher levels of poverty and rural residence were associated with being uninsured versus having non-Medicaid insurance [19]. Uninsured patients are less likely to schedule recommended surgery due to potential economic constraints. On the other hand, individuals with financial capacity and social support may have easier access to high-quality home and hospital care, which might lead to potential advantages in survival outcome [20]. Insured individuals are more likely to have regular access to health care [21]. An alternative explanation is that uninsured patients may experience medical comorbidities that potentially preclude surgical treatment, while insured patients may have lower levels of comorbidity. As SEER dataset did not provide detailed information about patient comorbidity, we could not further investigate this correlation.
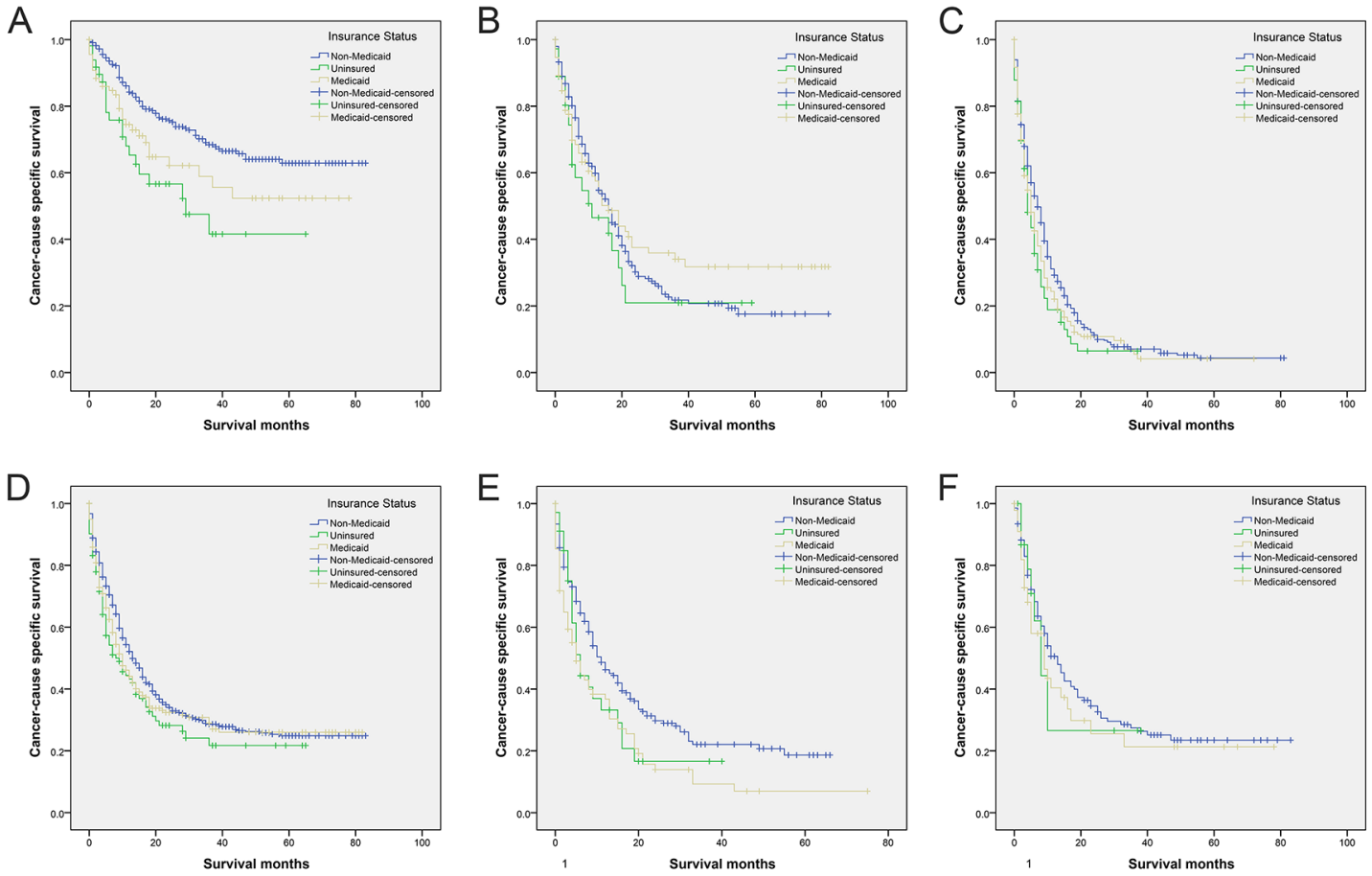

Figure 3: Survival curves in gallbladder cancer patients according to insurance status. (A) SEER localized stage: $\chi 2=$ $14.140(P=0.001)$; (B) SEER regional stage: $\chi 2=2.139(P=0.343)$; (C) SEER distant stage: $\chi 2=9.093(P=0.011)$; (D) White: $\chi 2=6.540$ $(P=0.038)$; (E) Black: $\chi 2=10.508(P=0.005)$; (F) American Indian/Alaska native, Asian/Pacific Islander: $\chi 2=0.922(P=0.675)$. 
Table 3: Univariate and multivariate survival analysis of insurance status on gallbladder cancer cause-specific survival based on different SEER stages

\begin{tabular}{|c|c|c|c|c|c|}
\hline \multirow[t]{2}{*}{ Variable } & \multirow[t]{2}{*}{ 3-year CCS } & \multicolumn{2}{|c|}{ Univariate analysis } & \multicolumn{2}{|c|}{ Multivariate analysis } \\
\hline & & $\begin{array}{l}\text { Log rank } \chi 2 \\
\text { test }\end{array}$ & $\boldsymbol{P}$ & HR $(95 \%$ CI) & $\boldsymbol{P}$ \\
\hline \multicolumn{6}{|l|}{ SEER stage } \\
\hline \multicolumn{6}{|l|}{ Localized } \\
\hline Insurance status & & 14.140 & 0.001 & & 0.006 \\
\hline Non-medicaid & $68.4 \%$ & Reference & & Reference & \\
\hline Uninsured & $41.6 \%$ & 12.258 & $<0.001$ & $\begin{array}{c}2.122(1.297- \\
3.473)\end{array}$ & 0.003 \\
\hline Medicaid & $58.9 \%$ & 5.435 & 0.020 & $\begin{array}{c}1.590(1.038- \\
2.435)\end{array}$ & 0.033 \\
\hline \multicolumn{6}{|l|}{ Regional } \\
\hline Insurance status & & 2.139 & 0.343 & & $\mathrm{NI}$ \\
\hline Non-medicaid & $21.8 \%$ & Reference & & & \\
\hline Uninsured & $20.9 \%$ & 1.218 & 0.270 & & \\
\hline Medicaid & $34.0 \%$ & 0.792 & 0.373 & & \\
\hline \multicolumn{6}{|l|}{ Distant } \\
\hline Insurance status & & 9.093 & 0.011 & & NI \\
\hline Non-medicaid & $7.1 \%$ & Reference & & & \\
\hline Uninsured & $6.5 \%$ & 6.312 & 0.012 & & \\
\hline Medicaid & $5.5 \%$ & 4.651 & 0.031 & & \\
\hline
\end{tabular}

SEER: Surveillance, Epidemiology, and End Results; CCS: cancer cause-specific survival; HR: hazard ratio; CI: confidence interval; NI: not included in the multivariate survival analysis.

Medicaid beneficiaries were described as underinsured or inadequately insured in other types of malignancies such as lymphoma, pediatric cancers and head and neck cancers $[22,23]$. Interestingly, the results according to the multivariate analyses suggested that there were no significant differences between non-Medicaid patients and Medicaid beneficiaries in $\operatorname{GBC}(P=0.162)$. Nevertheless, uninsured patients had worse survival outcome compared to patients with insurance coverage (Non-Medicaid or Medicaid). Further studies with larger sample size are needed to verify this finding.

In spite of our efforts to make a comprehensive and accurate analysis, there are several limitations to this study. First, the retrospective nature of this study may lead to bias and potentially have an influence on the results. Second, it has been widely acknowledged that the operation methods and comorbidities have an impact on the prognosis of cancer patients. As the variables provided in SEER database were limited, we could not adjust the results for these covariates. Third, information on the duration of insurance was not provided in SEER dataset.
As a result, we could not distinguish between those who had Medicaid coverage for many years and those enrolled at the time of diagnosis. Fourth, the insurance information for those aged 65 years or older is currently not clearly recorded in SEER database, therefore we excluded this age population. Fifth, income and education status at individual level were unobtainable from SEER dataset, and both of these variates might result in treatment decisions. Finally, it is noteworthy that this study was limited as the results shown can only demonstrate the correlation in specific SEER regions and should be interpreted with cautions while being applied in other regions. The underregistration and misclassification within and among counties might also result in bias.

In conclusion, we found that insurance status was an independent predictor for survival in patients with GBC. Uninsured individuals were at the highest risk compared to non-Medicaid patients and Medicaid recipients. Subgroup analysis suggested the uninsured status independently predicted unfavorable survival outcome at localized stage and in white individuals with GBC. Future studies 
Table 4: Univariate and multivariate survival analysis of insurance status on gallbladder cancer cause-specific survival based on different ethnicities

\begin{tabular}{|c|c|c|c|c|c|}
\hline \multirow[t]{2}{*}{ Variable } & \multirow[t]{2}{*}{ 3-year CCS } & \multicolumn{2}{|c|}{ Univariate analysis } & \multicolumn{2}{|c|}{ Multivariate analysis } \\
\hline & & $\begin{array}{l}\text { Log rank } \chi^{2} \\
\text { test }\end{array}$ & $P$ & HR $(95 \%$ CI $)$ & $P$ \\
\hline \multicolumn{6}{|l|}{ Ethnicity } \\
\hline \multicolumn{6}{|l|}{ White } \\
\hline Insurance status & & 6.540 & 0.038 & & 0.028 \\
\hline Non-medicaid & $28.6 \%$ & Reference & & Reference & \\
\hline Uninsured & $21.7 \%$ & 5.546 & 0.019 & $\begin{array}{c}\text { 1. 421(1.109- } \\
1.822)\end{array}$ & 0.005 \\
\hline Medicaid & $29.0 \%$ & 2.328 & 0.127 & $\begin{array}{c}1.040(0.870- \\
1.244)\end{array}$ & 0.665 \\
\hline \multicolumn{6}{|l|}{ Black } \\
\hline Insurance status & & 10.508 & 0.005 & & NI \\
\hline Non-medicaid & $22.1 \%$ & Reference & & & \\
\hline Uninsured & $16.6 \%$ & 2.302 & 0.129 & & \\
\hline Medicaid & $9.3 \%$ & 9.639 & 0.002 & & \\
\hline \multicolumn{6}{|c|}{$\begin{array}{l}\text { American Indian/Alaska } \\
\text { native and Asian/Pacific } \\
\text { Islander }\end{array}$} \\
\hline Insurance status & & 0.922 & 0.630 & & NI \\
\hline Non-medicaid & $27.4 \%$ & Reference & & & \\
\hline Uninsured & $26.6 \%$ & 0.176 & 0.675 & & \\
\hline Medicaid & $21.3 \%$ & 0.864 & 0.353 & & \\
\hline
\end{tabular}

CCS: cancer cause-specific survival; HR: hazard ratio; CI: confidence interval; NI: not included in the multivariate survival analysis.

are needed to validate these findings and investigate the underlying mechanisms of survival disadvantage in uninsured patients.

\section{MATERIALS AND METHODS}

\section{Patient selection in the SEER database}

All primary data were extracted from the SEER database using SEER*Stat version 8.3.2. The SEER includes population-based cancer populations reported in the Alaska, California, Connecticut, Georgia, Hawaii, Iowa, Kentucky, Louisiana, Michigan, New Jersey, New Mexico, Utah, and Washington registries, representing approximately $28 \%$ of the population in the United States. The SEER data have been widely used for studies investigating the relationship between insurance status and tumor characteristics [24-26].

GBCs were identified by the topography code C23.9 for gallbladder with the following
International Classification of Diseases for Oncology, $3^{\text {rd }}$ Edition (ICD-O-3) codes as previously reported [17]: adenocarcinoma (8140, 8141, 8143 and 8147), mucinous adenocarcinoma (8480 and 8481), papillary adenocarcinoma (8260-8263), adenocarcinoma with metaplasia (8571-8576), duct carcinoma (8500, 8501, $8503,8504,8507$ and 8508), papillary carcinoma (8050$8052)$, squamous cell carcinoma (8070-8076 and 8078), adenosquamous carcinoma (8560 and 8562), or other cancers including signet ring (8490), small cell (8041 and 8043), giant and spindle cell (8030-8035), non-small cell carcinoma (8046), carcinoma not otherwise specified (8010-8015) or undifferentiated carcinoma (8020-8022).

Inclusion criteria were as follows: (1) patients with GBC as their primary diagnosis; (2) patients diagnosed with GBC in the time period from January $1^{\text {st }}, 2007$ to December $31^{\text {st }}, 2013$, considering that the SEER program began collecting insurance status in 2007. The exclusion criteria for patients included the following: (1) patients with unobtainable insurance information were excluded; 
(2) patients aged $<18$ years were excluded; (3) patients aged 65 years or older were excluded as it was the age that most patients are eligible for Medicare, which is currently not clearly coded for individuals in SEER program and not recommended to be used in this age population.

GCSS was the primary focus of this study, and was calculated from the date of diagnosis of GBC and the date of GBC cause-specific death. Deaths attributed to GBC were treated as events, and deaths from other causes were treated as censored observations.

\section{Patient demographics and clinicopathological variables}

Potentially relevant patient and clinicopathological variables were included in the analyses. Insurance status was defined as non-Medicaid (including non-Medicaid and no specifics), uninsured, and Medicaid (any Medicaid). Tumor size was categorized into two groups: $<3.5 \mathrm{~cm}$ and $\geq 3.5 \mathrm{~cm}$. The selected cutoff value of $3.5 \mathrm{~cm}$ represented the median size of all GBC. The TNM stage was established according to the criteria described in the American Joint Committee on Cancer staging atlas (the $6^{\text {th }}$ edition). According to the SEER staging system, diseases that confined to the organ of origin were defined as localized, diseases that invaded locally or metastasized to regional lymph nodes were considered to be regional, and diseases that spread to remote organs were regarded as distant. Household income and level of education could not be obtained in SEER as individual-level data, and therefore we used county-level data. Median household income within the county of residence at the time of diagnosis was chosen to represent the county-level income level at the time of diagnosis, and percentage of adult individuals with at least a bachelor's degree was selected to represent the county-level education level.

\section{Statistical analysis}

Differences in baseline parameters were analyzed by chi-squared $(\chi 2)$ test for categorical variables. Survival curves were generated using the Kaplan-Meier estimates, and log-rank $\chi 2$ tests were performed to compare differences between subgroups of each variable. Multivariate Cox proportional hazard models were built to determine risk factors for survival outcomes. Results were considered statistically significant when a twosided $P$ value less than 0.05 was achieved. All statistical analyses were conducted using SPSS software (version 21.0; Statistics Package for Social Science, Chicago, IL).

\section{Abbreviations}

GBC: gallbladder cancer; SEER: Surveillance, Epidemiology, and End Results; GCSS: gallbladder cancer cause-specific survival; HR: hazard ratio; CI: confidence interval; ICD-O-3: International Classification of Diseases for Oncology, 3rd Edition

\section{ACKNOWLEDGMENTS}

This work was supported by grants from National Natural Science Foundation of China (grant no. 81521004, $81300363,81270553,81572262)$, Natural Science Foundation of Jiangsu Province (BK20151583), Jiangsu Province's Key provincial Talents Program, 333 high class Talented Man Project (BRA2016516), Six Talents peak project of Jiangsu province (2013-wsn-032), and Jiangsu Youth Medical Talents (QNRC2016580).

\section{CONFLICTS OF INTEREST}

The authors declare no conflicts of interest.

\section{REFERENCES}

1. Hundal R, Shaffer EA. Gallbladder cancer: epidemiology and outcome. Clin Epidemiol. 2014; 6:99-109. doi:10.2147/ CLEP.S37357.

2. Nogueira L, Freedman ND, Engels EA, Warren JL, Castro F, Koshiol J. Gallstones, cholecystectomy, and risk of digestive system cancers. Am J Epidemiol. 2014; 179:7319. doi:10.1093/aje/kwt322.

3. Hossain AM, Khozouz RF, Rahman RN. Epidemiology, treatment outcome, and survival of primary gallbladder cancer in the United States: a period prevalence SEER database study 1973-2007. J Clin Oncol. 2011; 29:4104. doi:10.1200/jco.2011.29.15_suppl.4104.

4. Randi G, Malvezzi M, Levi F, Ferlay J, Negri E, Franceschi S, La Vecchia C. Epidemiology of biliary tract cancers: an update. Ann Oncol. 2009; 20:146. doi:10.1093/annonc/mdn533.

5. Henley SJ, Weir HK, Jim MA, Watson M, Richardson LC. Gallbladder cancer incidence and mortality, United States 1999-2011. Cancer Epidemiol Biomarkers Prev. 2015; 24:1319. doi:10.1158/1055-9965.EPI-15-0199.

6. Rahman R, Simoes EJ, Schmaltz C, Jackson CS, Ibdah JA. Trend analysis and survival of primary gallbladder cancer in the United States: a 1973-2009 population-based study. Cancer Med. 2017; 6:874-80. doi:10.1002/cam4.1044.

7. Li Z, Yu X, Shen J, Law PT, Chan MT, Wu WK. MicroRNA expression and its implications for diagnosis and therapy of gallbladder cancer. Oncotarget. 2015; 6:13914-21. doi:10.18632/oncotarget.4227.

8. Costa LJ, Brill IK, Brown EE. Impact of marital status, insurance status, income, and race/ethnicity on the survival of younger patients diagnosed with multiple myeloma in the United States. Cancer. 2016; 122:3183-90. doi:10.1002/ cncr.30183.

9. Rong X, Yang W, Garzon-Muvdi T, Caplan JM, Xuan H, Lim M, Huang J. Influence of insurance status on survival 
of adults with glioblastoma multiforme: a population-based study. Cancer. 2016; 122:3157-65. doi:10.1002/cncr.30160.

10. Zaydfudim V, Whiteside MA, Griffin MR, Feurer ID, Wright JK, Pinson CW. Health insurance status affects staging and influences treatment strategies in patients with hepatocellular carcinoma. Ann Surg Oncol. 2010; 17:310411. doi:10.1245/s10434-010-1181-2.

11. Parikh AA, Robinson J, Zaydfudim VM, Penson D, Whiteside MA. The effect of health insurance status on the treatment and outcomes of patients with colorectal cancer. J Surg Oncol. 2014; 110:227-32. doi:10.1002/jso.23627.

12. Fintel AE, Jamy $\mathrm{O}$, Martin MG. Influence of insurance and marital status on outcomes of adolescents and young adults with acute lymphoblastic leukemia. Clin Lymphoma Myeloma Leuk. 2015; 15:364-7. doi:10.1016/j. clml.2014.12.006.

13. Andrén-Sandberg A. Diagnosis, management of gallbladder cancer. N Am J Med Sci. 2012; 4:203-11. doi:10.4103/1947-2714.98586.

14. Sirohi B, Mitra A, Jagannath P, Singh A, Ramadvar M, Kulkarni S, Goel M, Shrikhande SV. Neoadjuvant chemotherapy in patients with locally advanced gallbladder cancer. Future Oncol. 2015; 11:1501-9. doi:10.2217/ fon.14.308.

15. Tran T, Ethun CG, Pawlik TM, Buettner S, Idrees K, Isom CA, Fields RC, Krasnick B, Weber SM, Salem A, Martin RC, Scoggins CR, Shen P, et al. Histologic classification and grading enhances gallbladder cancer staging: a population-based prognostic score validated by the U.S. Extrahepatic Biliary Malignancy Consortium. J Clin Oncol. 2017; 35:356. doi:10.1200/JCO.2017.35.4_suppl.356.

16. Zaydfudim V, Feurer ID, Wright JK, Pinson CW. The impact of tumor extent ( $\mathrm{T}$ stage) and lymph node involvement ( $\mathrm{N}$ stage) on survival after surgical resection for gallbladder adenocarcinoma. HPB (Oxford). 2008; 10:420-7. doi:10.1080/13651820802320057.

17. Bai DS, Chen P, Qian JJ, Jin SJ, Jiang GQ. Effect of marital status on the survival of patients with gallbladder cancer treated with surgical resection: a population-based study. Oncotarget. 2017; 8:26404-13. doi:10.18632/ oncotarget.15476.
18. Aizer AA, Falit B, Mendu ML, Chen MH, Choueiri TK, Hoffman KE, Hu JC, Martin NE, Trinh QD, Alexander BM. Cancer-specific outcomes among young adults without health insurance. J Clin Oncol. 2014; 32:2025-30. doi:10.1200/JCO.2013.54.2555.

19. Grant SR, Walker GV, Guadagnolo BA, Koshy M, Allen PK, Mahmood U. Variation in insurance status by patient demographics and tumor site among nonelderly adult patients with cancer. Cancer. 2015; 121:2020-8. doi:10.1002/cncr.29120.

20. Virnig BA. Associating insurance status with cancer stage at diagnosis. Lancet Oncol. 2008; 9:189-91. doi:10.1016/ S1470-2045(08)70043-3.

21. Parsons HM, Schmidt S, Tenner LL, Bang H, Keegan THM. Early impact of the Patient Protection and Affordable Care Act on insurance among young adults with cancer: analysis of the dependent insurance provision. Cancer. 2016; 122:1766-73. doi:10.1002/cncr.29982.

22. Naghavi AO, Echevarria MI, Grass GD, Strom TJ, Abuodeh YA, Ahmed KA, Kim Y, Trotti AM, Harrison LB, Yamoah K. Having Medicaid insurance negatively impacts outcomes in patients with head and neck malignancies. Cancer. 2016; 122:3529-37. doi:10.1002/cncr.30212.

23. Koroukian SM, Bakaki PM, Raghavan D. Survival disparities by Medicaid status: an analysis of eight cancers. Cancer. 2011; 118:4271-9. doi:10.1002/cncr.2738.

24. Kamel M, Elfaramawi M, Jadhav S, Saafan A, Raheem $\mathrm{O}$, Davis R. Insurance status and differences in treatment and survival of testicular cancer patients. Urology. 2016; 87:140-5. doi:10.1016/j.urology.2015.06.059.

25. Rosenberg AR, Kroon L, Chen L, Li CI, Jones B. Insurance status and risk of cancer mortality among adolescents and young adults. Cancer. 2015; 121:1279. doi:10.1002/ cncr.29187.

26. Pan HY, Walker GV, Grant SR, Allen PK, Jiang J, Guadagnolo BA, Smith BD, Koshy M, Rusthoven CG, Mahmood U. Insurance status and racial disparities in cancer-specific mortality in the United States: a populationbased analysis. Cancer Epidemiol Biomarkers Prev. 2017; 26:869-75. doi:10.1158/1055-9965.EPI-16-0976. 